\title{
Correction to: Hanwell, et al. Zebrafish 2016 Jul;13/S1;S-153-S-163
}

The authors of the published article entitled, "Restrictions on the Importation of Zebrafish into Canada Associated with Spring Viremia of Carp Virus," request that Jennifer V. Robertson, whose name was inadvertently omitted from the author list, be added as one of the contributors to this paper.

Jennifer V. Robertson should have been listed just prior to Vincent Tropepe. The correct list of authors is below.

David Hanwell, ${ }^{1}$ Sarah A. Hutchinson, ${ }^{2}$ Chereen Collymore, ${ }^{3}$ Ashley E. Bruce, ${ }^{4}$ Rhain Louis, ${ }^{1}$ Ayoob Ghalami, ${ }^{5}$ W. Ted Allison, ${ }^{6}$ Marc Ekker, ${ }^{7}$ B. Frank Eames, ${ }^{8}$ Sarah Childs, ${ }^{9}$ Deborah M. Kurrasch, ${ }^{10}$ Robert Gerlai, ${ }^{4},{ }_{11}$ Tod Thiele, ${ }^{4,}{ }^{12}$ Ian Scott, ${ }^{13}$ Brian Ciruna, ${ }^{13}$ James J. Dowling, ${ }^{14}$ Sarah McFarlane, ${ }^{9}$ Peng Huang, ${ }^{9}$ Xiao-Yan Wen ${ }^{15}$ Marie-Andrée Akimenko, ${ }^{7}$ Andrew J. Waskiewicz, ${ }^{16}$ Pierre Drapeau, ${ }^{17}$ Lorne A. Babiuk, ${ }^{18}$ Dan Dragon, ${ }^{19}$ Andrea Smida, ${ }^{20}$ Andre (Gerald) Buret, ${ }^{21}$ Eoin O'Grady, ${ }^{22}$ Joanna Wilson, ${ }^{23}$ Lois Sowden-Plunkett, ${ }^{24}$ Jennifer V. Robertson, ${ }^{25}$ and Vincent Tropepe ${ }^{4}$

${ }^{25}$ Department of Biochemistry and Biomedical Sciences, McMaster University, Hamilton, Canada

The authors sincerely regret this oversight. 